\title{
Extra Virgin Olive Oil (Evoo) As A Valid Functional Food in the Oral Cavity
}

ISSN: 2640-9208

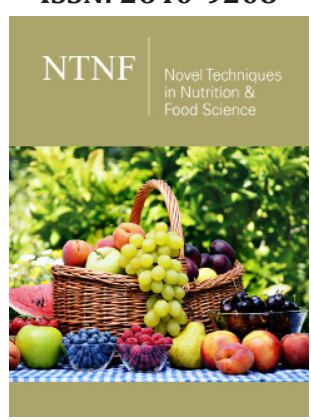

*Corresponding author: Antonia Sinesi, RDH, Freelancer in Canosa di Puglia, Italy

Submission: 眥January 15, 2021

Published: 嗹January 28, 2021

Volume 5 - Issue 4

How to cite this article: Antonia Sinesi, Ruggiero Damato. Extra Virgin Olive Oil (Evoo) As A Valid Functional Food in the Oral Cavity. Nov Tech Nutri Food Sci. 5(4). NTNF. 000617. 2021. DOI: 10.31031/NTNF.2021.05.000617

Copyright@ Antonia Sinesi. This article is distributed under the terms of the Creative Commons Attribution 4.0 International License, which permits unrestricted use and redistribution provided that the original author and source are credited.

\author{
Antonia Sinesi ${ }^{1 *}$ and Ruggiero Damato ${ }^{2}$ \\ ${ }^{1} \mathrm{RDH}$, Freelancer in Canosa di Puglia, Italy \\ ${ }^{2} \mathrm{RDH}$, Freelancer in Barletta, Italy
}

\section{Opinion}

The term "Functional Food" originated in Japan during the 1980s. Japan was the first country in the world to define the concept of functional foods by calling them FOSHU, an acronym that stands for "Food for specified health use" and which indicates a particular category of food or drink, which boast the ability to act on certain organs to prevent and treat particular ailments. A Functional Food is therefore a potentially healthy food, whose positive effect is attributable to intrinsically present components or to components it has been enriched with capable of interacting positively with the organism, obtaining a significant improvement in the state of health and well-being and/or a decrease in the risk of contracting chronic diseases.

Although there are a number of ways to define the term 'functional food' [1], to date, there is no universally accepted definition for this group of foods [2]. Several national authorities and scientific organizations have formulated definitions [3]. The International Food Information Council defines functional foods as "foods that may provide health benefits beyond basic nutrition" [4]. The American Dietetic Association defines functional foods as "foods that provide additional health benefits that may reduce disease risk and/or promote optimal health" [5]. The EU Project "Functional Food Science in Europe" specifies functional foods as "foods that are satisfactorily demonstrated to affect beneficially one or more target functions in the body, beyond adequate nutritional effects, in a way that is relevant to either an improved state of health and well-being and/or reduction of risk of disease" [6].

Among functional foods we find extra virgin olive oil (EVOO), an essential food of Mediterranean diet (MD) in the countries of the homonymous area such as Spain, Italy and Greece which represent the most important producers in the world. As documented by numerous studies published in recent decades, most of the beneficial effects of the Mediterranean diet on promoting human health can be attributed to EVOO [7]. Extra-virgin olive oil is regarded as functional food since epidemiological studies and multidisciplinary research have reported convincing evidence that its intake beneficially affects one or more target functions in the body, improves health and reduces risk of disease. Its health properties have been related to the major and minor component fractions of extra-virgin olive oil. Among olive oil chemical components, the phenolic fraction has received considerable attention due to its bioactivity in different chronic diseases. The bioactivity of the phenolic compounds could be related to different properties such as antioxidant and anti-inflammatory ones, although the molecular action mechanism of these compounds in relation to many diseases might have different cellular targets.

Its unique composition and biological properties are largely responsible for this association (Figure 1). The beneficial properties of EVOO have been attributed to its high content of monounsaturated fatty acids (MUFA), which represent up to $80 \%$ of its total lipid composition. However, recent evidence has shown that the minor components of EVOO, such as phenolic compounds and other compounds with antioxidant actions, determine an increase in the health characteristics of the oil itself [8]. These components make up only $1-2 \%$ of 
EVO and are completely absent in other types of oils derived from seeds or fruits [9]. The nutritional and antioxidant properties of EVOO are related to the presence and concentration of tocopherols, carotenoids and phenolic compounds which are of great importance for human health [10]. Extra virgin olive oils contain different classes of phenolic compounds such as phenyl alcohol (hydroxytyrosol and tyrosol), cynic acid (caffeic and p-coumaric acid) and benzoic acid (vanillic acid), flavones (apigenin and luteolin) and secoiridoids (oleuropein and ligtroside derivatives) [11]. The main polyphenol in EVOO, hydroxytyrosol, is a ROS scavenger. In EVOO we find oleuropein, an anti-inflammatory molecule that promotes the production of nitric oxide in macrophages [12] and oleocanthal which exerts an anti-inflammatory action similar to ibuprofen
$[13,14]$. EVOO itself is rich in vitamins D, A, E and helps the absorption of the whole group of fat- soluble vitamins. EVOO, rich in polyphenols, is able to reduce heterocyclic amines and plasma levels of $\mathrm{C}$ reactive protein [15]. Nutrigenomic studies by De Santis et al. [16] reveal that the EVOO cultivars characterized by a high content of polyphenols such as the "Coratina" [17] cultivar present in a geographical area of Puglia, are able to act on transcriptome and to modulate the expression of different miRNA transcripts involved in different pathways, for example glucose or lipid metabolism and cell proliferation, so polyphenols are fundamental biomolecules in nutrigenomic modulation. Therefore, the positive impact of EVOO on human health could be attributed to a synergistic effect of polyphenolic compounds with the high content of oleic acid.

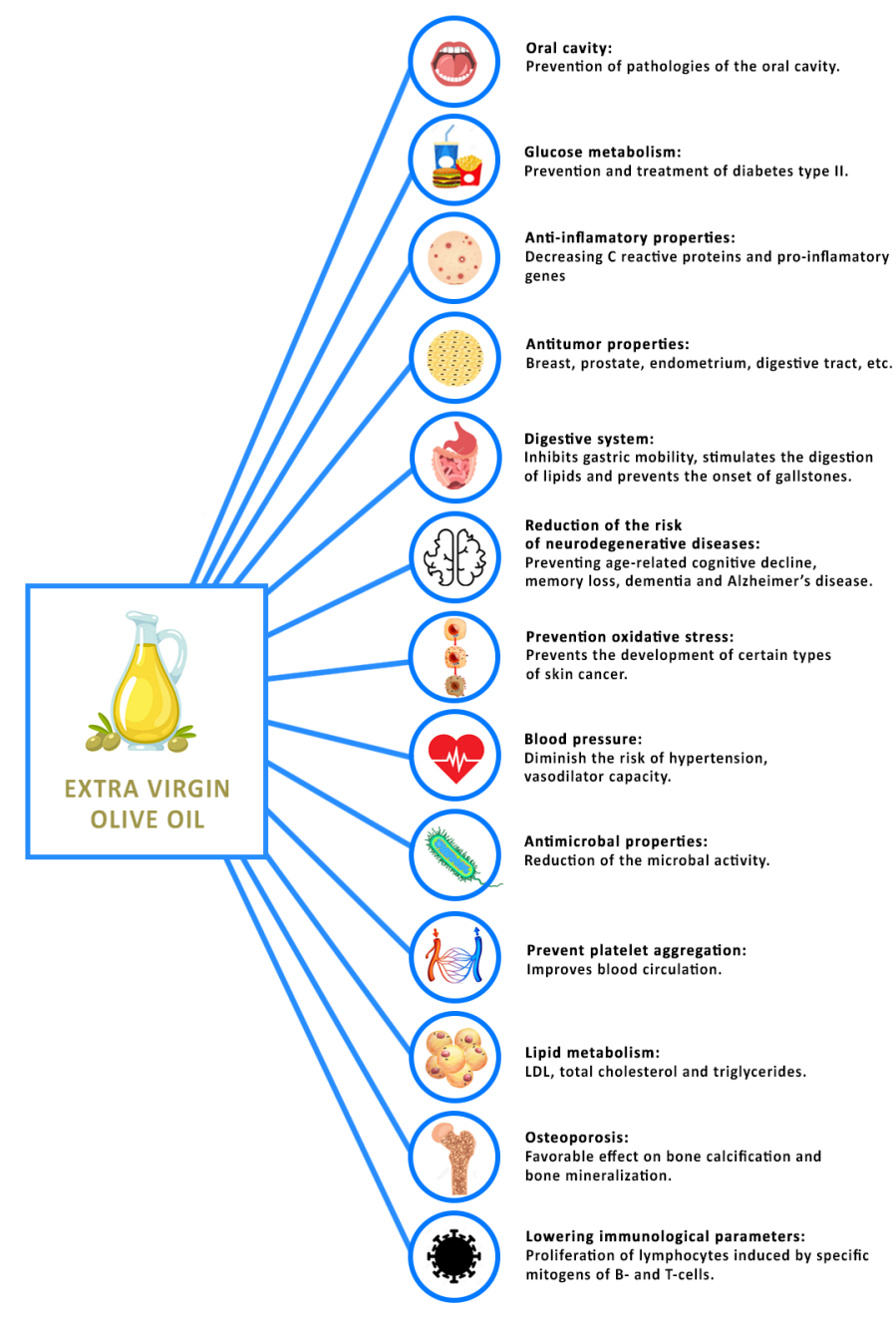

Figure 1:

In 2011 the European Food Safety Authority (EFSA) approved a health claim stating that the dietary intake of virgin olive oil (poly) phenols is able to protect blood lipids from oxidative damage. The panel considers that in order to bear the claim, $5 \mathrm{mg}$ of hydroxytyrosol and its derivatives should be consumed daily $[18,19]$. Extra virgin olive oil has such important beneficial properties that the FDA (Food and Drug Administration, USA government body) has included it in the superfood category, promoting it as a "drug" stating that the daily consumption of about 2 tablespoons, or 23 grams of olive oil, can reduce the risk of coronary heart disease. Due to these healthy properties, EVOO can also find a field of application in prevention and treatment of oral diseases. EVOO is used for treatment of oral 
mucosa lesions such as traumatic ulcers, reducing healing times [20]. Its mode of use as a therapeutic agent is the same as that of a mouthwash.

Studies in the literature show that it has positive effects on initial erosion of the enamel, [21] burning mouth syndrome [22,23], in prevention of oral cancer [24], in prevention and treatment of periodontal disease [25] and in treatment of mucositis following radiotherapy [26]. This functional food with extraordinary multifaceted and miraculous properties should be taken daily with food but could also be used to solve mouth problems especially affecting the oral mucosa. Use of EVOO could find application above all as a valid alternative to classic drug treatment.

\section{References}

1. Roberfroid MB (2002) Global view on functional foods: European perspectives. Br J Nutr 88(Suppl 2): S133-S138.

2. Alzamora SM, Salvatori D, Tapia MS, Malo AL, Chanes JWC, et al. (2005) Novel functional foods from vegetable matrices impregnated with biologically active compounds. J Food Eng 67(1-2): 205-214.

3. Kaur S, Das M (2011) Functional foods: An overview. Food Sci Biotechnol 20: $861-875$

4. https://foodinsight.org/2011-functional-foods-foods-for-healthconsumer-trending-survey/

5. Hasler CM, Bloch AS, Thomson CA (2004) Position of the american dietetic association: functional foods. J Am Diet Assoc 104(5): 814-826.

6. Diplock AT, Aggett PJ, Ashwell M, Bornet F, Fern EB, et al. (1999) Scientific concepts of functional foods in Europe-consensus document. Br J Nutr 81: 1-2.

7. Trichopoulou A, Gonzalez MA, Tong TY, Forouhi NG, Khandelwal S, et al. (2014) Definitions and potential health benefits of the Mediterranean diet: Views from experts around the world. BMC Med 12: 112.

8. Tripoli E, Giammanco M, Tabacchi G, Majo D, Giammanco S, et al. (2005) The phenolic compounds of olive oil: Structure, biological activity and beneficial effects on human health. Nutr Res Rev 18(1): 98-112.

9. Serrano EMY, Moreno JL, Delgado FG, Miranda JL (2019) Extra virgin olive oil: More than a healthy fat. Eur J Clin Nutr 72(Suppl 1): 8-17.

10. Ranalli F, Ranalli A, Contento S, Casanovas M, Antonucci M, et al. (2013) Bioactives and nutraceutical phytochemicals naturally occurring in virgin olive oil. The case study of the Nocellara del Belice Italian olive cultivar. Nat Prod Res 27: 1686-1690.

11. Debicka MG, Przychodzen P, Cappello F, Jankowska AK, Gammazza AM, et al. (2018) Potential health benefits of olive oil and plant polyphenols. Int J Mol Sci 19(3): 686.

12. Virruso C, Accardi G, Romano GC, Candore G, Vasto S, et al. (2014) Nutraceutical properties of extra-virgin olive oil: A natural remedy for age-related disease? Rejuvenation Res 17(2): 217-220.
13. Beauchamp GK, Keast RS, Morel D, Lin J, Pika J, et al. (2005) Phytochemistry: Ibuprofen-like activity in extra-virgin olive oil. Nature 437(7055): 45-46.

14. Yadav TC, Kumar N, Raj U, Goel N, Vardawaj PK, et al. (2020) Exploration of interaction mechanism of tyrosol as a potent anti-inflammatory agent. J Biomol Struct Dyn 38(2): 382-397.

15. Monti SM, Ritieni A, Sacchi R, Skog K, Borgen E, et al. (2001) Characterization of phenolic compounds in virgin olive oil and their effect on the formation of carcinogenic/mutagenic heterocyclic amines in a model system. J Agric Food Chem 49(8): 3969-3975.

16. Santis S, Cariello M, Piccinin E, Sabbà C, Moschetta A (2019) Extra virgin olive oil: lesson from nutrigenomics. Nutrients. 11(9): E2085.

17. Coco L, Pascali SA, Fanizzi FP (2014) ${ }^{1} \mathrm{H}$ NMR spectroscopy and multivariate analysis of monovarietal evoos as a tool for modulating CORATINA-based blends. Foods 3(2): 238-249.

18. EFSA Panel on Dietetic Products, Nutrition and Allergies (NDA) (2012) Scientific Opinion on the substantiation of a health claim related to polyphenols in olive and maintenance of normal blood HDL cholesterol concentrations (ID 1639, further assessment) pursuant to Article 13(1) of Regulation (EC) No 1924/2006. EFSA J 10(8): 2848.

19. Tetens I EFSA Panel on Dietetic Products, Nutrition and Allergies (NDA) (2011) Scientific Opinion on the Substantiation of a health claim related to glucosamine and maintenance of Lycopene, Proanthocyanidins, Vitamin C, Vitamin E, Selenium and Beta-Carotene and contribution to Normal Collagen Formation (ID 1669) and protection of the skin from UV-induced damage (ID 1669) pursuant to article 13(1) of regulation (EC) No 1924/2006. European Food Safety Authority (EFSA) 9(6): 2239.

20. Sinesi A, Casu C, Cefola S, Damato R, Orrù G (2020) Use of extra virgin olive oil (EVOO) in the treatment of traumatic ulcers. A case report. Journal of Biomedical Practitioners 4(1-19): 25.

21. Ionta FQ, Alencar CRB, Val PP, Boteon AP, Jordão MC, et al. (2017) Effect of vegetable oils applied over acquired enamel pellicle on initial erosion. J Appl Oral Sci 25(4): 420-426.

22. Carrillo PC, Fuster AP, Jornet PL (2014) Efficacy of lycopene-enriched virgin olive oil for treating burning mouth syndrome: a double-blind randomised. J Oral Rehabil 41(4): 296-305.

23. Liu YF, Kim Y, Yoo T, Han P, Inman JC (2018) Burning mouth syndrome: a systematic review of treatments. Oral Dis 24(3): 325-334.

24. Franceschi S, Favero A, Conti E, Talamini R, Volpe R, et al. (1999) Food groups, oils and butter, and cancer of the oral cavity and pharynx. Br J Cancer 80(3-4): 614-620.

25. Kubitza FML, Anthony JMG (2019) Topical oral 1-tetradecanol complex in the treatment of periodontal diseases in cats. J Feline Med Surg 21(12): 1141-1148.

26. Abdulrhman M, Elbarbary NS, Amin DA, Ebrahim RS (2012) Honey and a mixture of honey, beeswax, and olive oil-propolis extract in treatment of chemotherapy-induced oral mucositis: a randomized controlled pilot study. Pediatr Hematol Oncol 29(3): 285-292.. 